\title{
A case of widespread molluscum contagiosum
}

\section{caused by baricitinib, a Janus kinase inhibitor}

Authors: Gwyneth Natalie Wong ${ }^{1}$, Senhong Lee ${ }^{1}$, Peter Foley ${ }^{1}$

${ }^{1}$ Skin and Cancer Foundation Inc

Running title: Molluscum contagiosum due to baricitinib

Corresponding Author: Gwyneth Natalie Wong

Ph: 0413768438

Email: g.natalie.wong@gmail.com

Postal address: 202/46 Cambridge St Collingwood, VIC, 3066

Word count: 497

The authors declare no conflicts of interest.

Patient consent has been obtained for the content and images used.

All authors confirm this is previously unpublished work with no submissions or related papers from the same study.

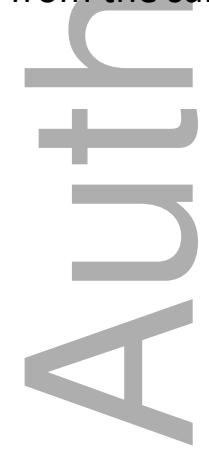

This is the author manuscript accepted for publication and has undergone full peer review but has not been through the copyediting, typesetting, pagination and proofreading process, which may lead to differences between this version and the Version of Record. Please cite this article as doi: $10.1111 /$ AJD.13059

This article is protected by copyright. All rights reserved 


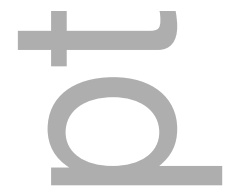

Article type : Case Letter

\section{A case of widespread molluscum contagiosum}

\section{caused by baricitinib, a Janus kinase inhibitor}

A 31-year-old male with a history of severe childhood onset atopic dermatitis (AD) was involved in a phase III clinical trial of baricitinib, an oral Janus kinase (JAK)1 and 2 inhibitor. In the long term extension arm of the study, the patient was placed on either $2 \mathrm{mg}$ or $4 \mathrm{mg}$ baricitinib and within 2 weeks began to develop multiple 2-3mm diameter flesh-coloured papules on his trunk. The eruption spread to include his neck and bilateral thighs over the subsequent four weeks and umbilication of the lesions was increasingly apparent. A clinical diagnosis of molluscum contagiosum was made. The lesions persisted despite 8 weeks of treatment with daily Duofilm @ (salicylic acid 16.7\%/ lactic acid 16.7\%) (Figure 1) and subsequently one application of topical cantharidin 1\%/salicylic acid 30\%/ podophyllin $2 \%$ mixture. Screening for tuberculosis and human immunodeficiency virus had been performed at the start of the study and was negative. The patient decided to withdraw from the study at week 24 due to persistent molluscum lesions and only mild improvement in AD - Eczema Area Severity Index (EASI) 22.7 reduced from 36.8 and body surface area (BSA) 39\% reduced from $60 \%$. Four weeks after ceasing baricitinib the patient's AD remained stable and there was a marked reduction in molluscum lesions without any additional treatment. A few lesions persisted on the trunk, as well in areas of the neck and groin where the patient regularly shaved. The patient opted to trial conservative management, with possible treatment with curettage in the near future if these lesions did not self resolve. 
JAK inhibitors are increasingly being used to treat rheumatoid arthritis and other inflammatory diseases, with evidence emerging of its efficacy in AD. ${ }^{1}$ JAKs are integral to the innate antiviral response and the use of JAK inhibitors appears to increase the risk of viral infections, particularly herpes zoster. ${ }^{2}$ There has been one other reported case of disseminated molluscum contagiosum caused by a JAK1 and 2 inhibitor, ruxolitinib, which was used to treat polycythaemia vera in a 49-year-old man with no history of dermatological disease. ${ }^{3}$ This patient had almost complete spontaneous regression when the dose of ruxolitinib was decreased without additional molluscum specific treatment.

Molluscum contagiosum is a benign viral infection of the skin that most commonly affects children or immunosuppressed adults. It can have an atypical and widespread presentation and be difficult to eradicate in an immunosuppressed individual. ${ }^{4}$ Patients with $\mathrm{AD}$ have an impaired barrier function that may make them more susceptible to molluscum contagiosum. ${ }^{5}$ In the paediatric population, the number of areas of the body affected by molluscum has been shown to be greater in patients with $\mathrm{AD}$ than those without. ${ }^{6}$ The use of topical antiinflammatory drugs for treatment of AD may further increase the risk of infection. ${ }^{5}$

Molluscum contagiosum should be recognised as a potential complication of JAK inhibitors, particularly in predisposed patients such as those with impaired skin barrier function. Treatment reduction or cessation of the JAK inhibitor, along with targeted treatment for the molluscum infection, may be required for clinical improvement.

\section{REFERENCES}

1. Cotter DG, Schairer D, Eichenfield L. Emerging therapies for atopic dermatitis: JAK inhibitors. Journal of the American Academy of Dermatology. 2018;78(3 Suppl 1):S53-S62. doi:10.1016/j.jaad.2017.12.019.

2. Winthrop KL. The emerging safety profile of JAK inhibitors in rheumatic disease. Nat ReV Rheumatol. 2017;13(4):234-243. doi:10.1038/nrrheum.2017.23.

3. Kinoshita M, Ogawa Y, Kawamura T, Kirito K, Shimada S. Case of disseminated molluscum contagiosum caused by ruxolitinib, a Janus kinase 1 and 2 inhibitor. J Dermatol. 2016;43(11):1387-1388. doi:10.1111/1346-8138.13404. 
4. Kaufman WS, Ahn CS, Huang WW. Molluscum contagiosum in immunocompromised patients: AIDS presenting as molluscum contagiosum in a patient with psoriasis on biologic therapy. Cutis. 2018;101(2):136-140.

5. Dekio I. Microorganisms and Atopic Dermatitis. In: Atopic Dermatitis - Disease Etiology and Clinical Management. InTech; 2012. doi:10.5772/25374.

6. Seize MB de MP, Ianhez M, Cestari SDCP. A study of the correlation between molluscum contagiosum and atopic dermatitis in children. An Bras Dermatol. 2011;86(4):663-668.

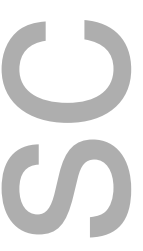

Figure 1.

4 weeks into treatment with Duofilm ${ }^{\circledR}$, disseminated papules persisting on the (a) trunk, (b) neck and thigh (not pictured) of the patient. (c) Molluscum lesion on lower trunk viewed under dermoscopy, showing characteristic white lobules with a surrounding crown of vessels

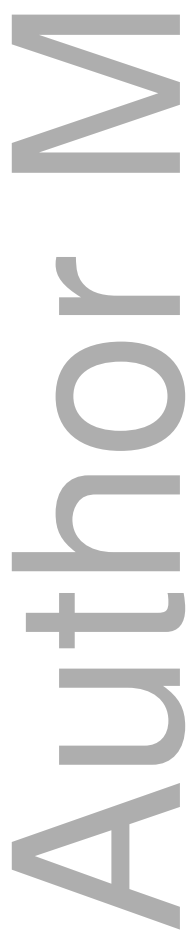




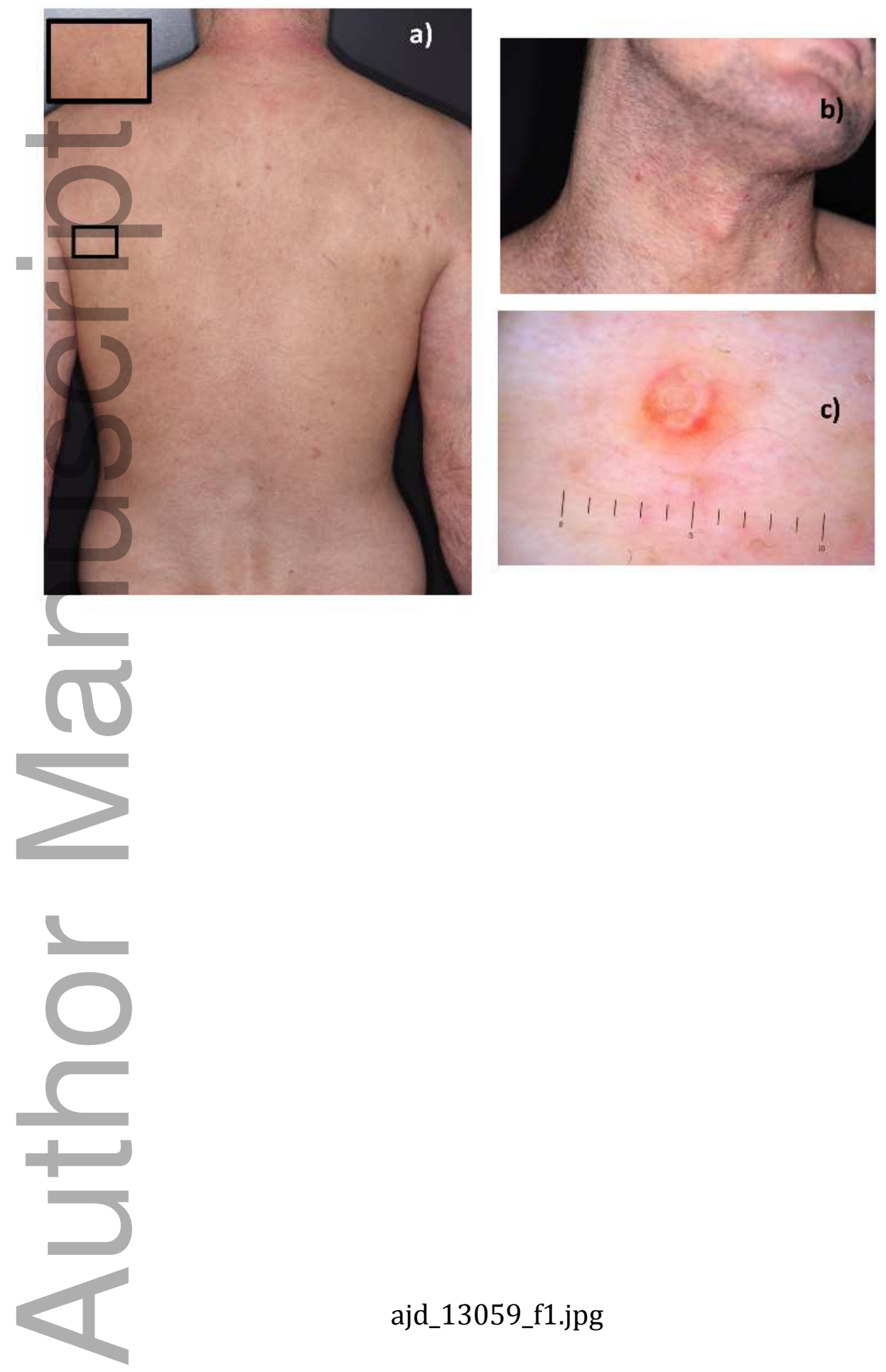

This article is protected by copyright. All rights reserved 


\section{University Library}

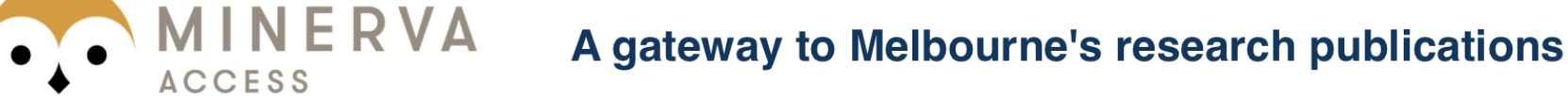

Minerva Access is the Institutional Repository of The University of Melbourne

Author/s:

Wong, GN;Lee, S;Foley, P

Title:

A case of widespread molluscum contagiosum caused by baricitinib, a Janus kinase inhibitor.

Date:

2019-11

Citation:

Wong, G. N., Lee, S. \& Foley, P. (2019). A case of widespread molluscum contagiosum caused by baricitinib, a Janus kinase inhibitor.. Australas J Dermatol, 60 (4), pp.e334-e335. https://doi.org/10.1111/ajd.13059.

Persistent Link:

http://hdl.handle.net/11343/285767 